\title{
Mechanical and corrosion properties of two precipitation hardened Mg-Y-Nd-Gd-Dy alloys with small changes in chemical composition
}

\author{
P. MAIER,,$^{1,4}$ N. LAUTH ${ }^{1}$, C.L. MENDIS ${ }^{2}$, M. BECHLY ${ }^{1}$, N. HORT ${ }^{3}$ \\ 1. University of Applied Science Stralsund, Stralsund, Germany \\ 2. Brunel University London, Brunel Centre for Advanced Solidification Technology, London, UK \\ 3. Helmholtz-Zentrum Geesthacht, Geesthacht, Magnesium Innovation Centre, Germany 4. e-mail: petra.maier@hochschule-stralsund.de
}

Precipitation hardening in Mg-Y-Nd alloys is based on finely dispersed particles an effective strengthening mechanism to achieve high strength at moderate ductility. However, these particles often affect corrosion by being more noble than the matrix. Biodegradable implant materials should show a corrosion rate fit to its application but should be free of pitting corrosion. Especially deep and narrow pits act as notches and cause increased mechanical stress leading into early failure. WE43 has already shown to have an acceptable biological response. In this study two Mg-Y-Nd-Gd-Dy alloys, WE32 and WE33, in extruded, solution and precipitation heat-treated conditions have been investigated. The difference in alloy composition is not very high. Solution heat treatment causes grain growth and strength loss. The ageing response to peak hardness depends on the temperature. A rather short ageing response was observed for $250{ }^{\circ} \mathrm{C}$ and for $200{ }^{\circ} \mathrm{C}$ highest hardness has been found at longer ageing time, but higher hardness compared to $250{ }^{\circ} \mathrm{C}$. Grain growth during ageing is not significant. The higher alloyed alloy WE33 shows better mechanical strength, but less ductility. Corrosion was evaluated with immersion and potentiodynamic polarization in Ringer Acetate solution. The corrosion rate strongly depends on the alloy and heat treatment condition as well as on the test method. The highest corrosion rate is observed in the T4 condition. The peak aged alloy shows the lowest corrosion rate, but non-uniform corrosion - in this evaluated by the pitting factor.

\section{Introduction and Motivation}

The commercial alloy WE43 (Mg-4Y-3RE, where RE is mostly a mixture of Rare-Earth elements like Ce or Nd) is preferentially under investigation as implant materials. WE43 is an alloy with an acceptable biological response, relatively slow degradation in aqueous solutions, good electro-chemical properties and excellent mechanical and corrosion properties [1,2]. Therefore, WE43 alloy is suggested to be a suitable candidate for implant application material [3-5] and already applied as bone screws and stents [6,7]. Two hot extruded Mg-Y-RE alloys are used in this study and contain slightly smaller amounts of total alloying additions compared with the commercial WE43 [8]. Alloys of WE type are conventionally used in the T6 condition and the intermetallic particles are fully characterized [9-12]. Intermetallic particles $\mathrm{Mg}_{12} \mathrm{Nd}_{\mathrm{d}}$ and $\mathrm{Mg}_{14} \mathrm{Y}_{4} \mathrm{Nd}$ are both observed in Mg-Y-Nd and the mechanical properties of the alloy depend strongly on the volume fraction and spatial distribution of these intermetallic phases.

This work investigates the influence of the intermetallic particles of two extruded alloys containing small amounts of Gd and Dy in addition to $\mathrm{Y}$ and $\mathrm{Nd}$ on mechanical properties, mostly by looking at the hardness and on corrosion properties, especially on the corrosion rate and corrosion morphology. In biomedical applications, an appropriatly slow (to avoid fast hydrogen evolution), uniform corrosion is needed. Corrosion pits cause additional mechanical loading and acts as crack tips which increase stress intensity and should be avoided. Where pitting is the predominant form of attack the extent and type of pitting may be evaluated in accordance with ASTM G46-76 [13]. Deep and narrow pits as well as undercutting pits are most harmful; wide and shallow pits are least harmful.

The pitting factor is calculated by $\mathrm{p} / \mathrm{d}$, where $\mathrm{p}$ is the deepest penetration and $\mathrm{d}$ the average penetration depth. Either crosssectional micrographs or $3 \mathrm{D}$ light microscopy imaging evaluates the value $\mathrm{p}$. The average penetration depth $\mathrm{d}$ is either evaluated by the corrosion rate by the weight loss method for the immersion tests or by the average depth of the corroded area of the cross-sectional micrograph. However, pits may overlap to give the appearance of a rough surface. High pitting factor values indicate a greater susceptibility to pitting corrosion while a pitting factor of 1 relates to an uniform corrosion. The mechanical properties required for bone implants are still under discussion, they should maintain mechanical integrity over a time scale of 12 to 18 weeks while the bone tissue heals and replaced by natural tissue $[14,15]$. The allowable strength loss depends on the application itself and influenced by the bone density and extent of damage on the bone fracture. 


\section{Experimental}

Alloys investigated were cast at Helmholtz-Zentrum Geesthacht under a protective gas mixture of $\mathrm{Ar}$ and $2 \% \mathrm{SF}_{6}$ and then hot extruded at the Extrusion Research and Development Center TU Berlin at an overall temperature of $420{ }^{\circ} \mathrm{C}$, a product speed of $2.2 \mathrm{~m} / \mathrm{min}$ and an extrusion ratio of 37 . For the analysis of the overall chemical composition, inductively coupled plasma-optical emission spectroscopy (ICPOES) was applied.

The alloys were solution treated (T4) at $525{ }^{\circ} \mathrm{C}$ for $8 \mathrm{~h}$ and quenched into warm water at $55^{\circ} \mathrm{C}$ to avoid quenching stresses. Precipitation hardening (T6) was done at $200{ }^{\circ} \mathrm{C}$ and $250^{\circ} \mathrm{C}$. Lower ageing temperatures will lead to higher peak age hardness [11], but higher ageing temperature keeps the time for peak ageing low and the ductility at a moderate level. In accordance with [12] peak ageing at $250{ }^{\circ} \mathrm{C}$ was expected within 10 hours. To avoid natural ageing the T6 treatment was done within a few hours after T4 or samples were stored in refrigerator temperatures. The samples (discs of a diameter of 17 $\mathrm{mm}$ ) for metallographic and hardness investigations were prepared according to Kree [16]. The line inspection method was used for grain size measurements. To evaluate the influence of the heat treatment on corrosion smaller cylinders (overall diameter of $14 \mathrm{~mm}$ and height of $10 \mathrm{~mm}$ ) were used in potentiodynamic polarization under application of Ringer-Acetate solution. 11 solution consist of $6 \mathrm{~g}$ sodium chloride, $3.7 \mathrm{~g}$ sodium acetate, $0.134 \mathrm{~g}$ calcium chloride, $0.203 \mathrm{~g}$ magnesium chloride and $0.4 \mathrm{~g}$ potassium chloride, with an initial $\mathrm{pH}$-value of 6.5 . The solution was applied at a constant temperature of $37{ }^{\circ} \mathrm{C}$ to fit body temperature. The potentiodynamic measurements were conducted on samples immediately after grinding with 1200 mesh paper, and cleaning in an ultrasonic bath in ethanol. A three-electrode flow cell using a counter electrode, an Argenthal reference electrode and a working electrode (with a measurement area of $\sim 95 \mathrm{~mm}^{2}-$ diameter of $11 \mathrm{~mm}$ ) was used to evaluate polarization (current density - potential) curves (glass chamber cell volume $\sim 170 \mathrm{ml}$ ).

A flow rate of 8 1/min (overall electrolyte volume was 3.6 1) was used to keep the pH-value around 8.5. Li et al. [17] have shown that the local corrosion behavior and the corrosion rate is strongly dependent on the flow of the electrolyte and WE43 is more susceptible to corrosion in a flowing solution. The shear stress applied by the flow promotes local corrosion. Static tests show usually lower corrosion rates. To force the $\mathrm{Mg}$ alloy into strong anodic corrosion the curve was traced with a scan rate of $50 \mathrm{mV} / \mathrm{min}$ from the negative potential end of $-2000 \mathrm{mV}$ towards the positive end of $+500 \mathrm{mV}$. The key point of this measurement is to study the passive/trans-passive behavior and corrosion morphology. The passive/trans-passive behavior is described by passivation current density and potential as well as the passive or pseudo-passive current density. Within the passive zone the current-density decreases significantly with increased potential (within the anodic corrosion part of the curve), where the pseudo-passive zone shows static current-density values.

Furthermore, immersion tests were performed using 3 samples for each condition. Cylindrical samples had a diameter of 15 $\mathrm{mm}$ and a height of $10 \mathrm{~mm}$ and were exposed to $500 \mathrm{ml}$ at $37^{\circ} \mathrm{C}$ for 7 days. The solution was changed after 4 days to avoid an increase in $\mathrm{pH}$ value. The weight loss was measured by removing the corrosion products with chromic acid. The mean corrosion rate was measured by using the following equation, where $\Delta \mathrm{m}$ is the weight change in $\mathrm{g}$, A the surface area sample in $\mathrm{cm}^{2}, \mathrm{t}$ the immersion time in $\mathrm{h}$ and $\rho$ the density in $\mathrm{g} / \mathrm{cm}^{3}$.

$C R_{m}=\frac{8.76 \times 10^{4} \times \Delta m}{A \times t \times \rho}$

Corrosion behavior was discussed by considering the visual changes of the sample surface using light microscopy and the corrosion morphology was evaluated via 3D-imaging and measurements on the cross-section micrographs after sectioning. For determination of the pitting factor the deepest pit depth $p$ is divided by the average penetration depth $d$. To evaluate $p$ either cross-sectional micrographs or 3D light microscopy imaging is used. The average penetration depth $\mathrm{d}$ of the immersion test is evaluated by the corrosion rate using the weight loss method and calculated for 7 days of exposure. In polarization $\mathrm{d}$ is calculated by the corroded area of the cross-sectional micrograph and divided by the diameter of exposed area, here $\sim 11 \mathrm{~mm}$.

Tensile properties were measured at room temperature with a TIRA mechanical testing machine at an initial speed of 2.4 $\mathrm{mm} / \mathrm{min}$. Cylindrical samples, at least 5 per condition, with a gauge length of $20 \mathrm{~mm}$ and a diameter of $6 \mathrm{~mm}$ were used according to DIN EN ISO 6892-1. Vickers hardness (HV1) was tested with a universal hardness testing machine ZHU2.5 using a Zwick hardness tester. The sample surface was ground after cutting to reduce residual stresses and approximately 30 indents per test condition under a load of $1 \mathrm{~kg}(9.807 \mathrm{~N})$ were carried out and the averages are reported. 


\section{Results and Discussion}

The both alloys used were named in the basis of WE43: WE32 for Mg2.78Y1.43Nd0.43Gd0.41Dy and WE33 for the higher alloyed alloy Mg3.05Y-1.81Nd0.50Gd0.43Dy. In the hot extruded condition of WE32 has a hardness of $67.2 \pm 2.1 \mathrm{HV} 1$ and WE33 of $66.4 \pm 4.5 \mathrm{HV} 1$. The grain size of WE32 is at $15 \pm 7.9 \mu \mathrm{m}$ smaller than of WE33 at $21 \pm 5.8 \mu \mathrm{m}$. Even though the difference in hardness is not very significant, it seems the smaller grain size has a higher influence on the hardness than the higher amount of alloying elements additions.

Fig. 1a and b show the hardness and grain size profile of WE32 and WE33 influenced by the heat treatment, the supersaturated $\alpha$-phase (T4) shows lower hardness and ageing (T6) shows a hardening response. The hardness decrease during T4 is explained by the increase in grain size and the dissolution of majority of the intermetallic particles. The grain growth in WE33 is more pronounced (140 $\mu \mathrm{m}$ in WE33 compared to $102 \mu \mathrm{m}$ in WE32). Undissolved second phases could hinder the grain boundary mobility. Both alloys show also a different texture, WE33 has a pronounced non-basal texture with an intensity up to 6.5 , whereas WE32 has a lower basal texture with an intensity up to 2.1. How the higher amount of alloying additions influences the texture of this alloy is still under investigation, but an influence on preferred grain growth cannot be ruled out. The peak hardness during precipitation hardening strongly depends on the ageing temperature. Ageing at $250{ }^{\circ} \mathrm{C}$ leads to the peak aged condition already after $8 \mathrm{~h}$. WE33 reaches a slight hardness of $79.8 \mathrm{HV} 1$ compared to 77.3 HV1 of WE32 (Fig. 1a). The higher amount of alloying additions will increase the volume fraction of precipitates forming during T6. The grain size does not change much: a slight increase can be seen for WE33, whereas WE32 decreases slightly. In a study on another WE33 alloy, where precipitation hardening on a Mg-3.3Y-3.4Nd alloy was investigated [18], a strong decrease in grain size during ageing was found. It is shown that a reduction in the mean value of grain size likely to be based on the development on new fine grains during precipitation hardening, when recrystallization seems not to be finished during solution heat treatment. Ageing at $200{ }^{\circ} \mathrm{C}$ leads to a higher hardness but takes longer times: $92.7 \mathrm{HV} 1$ of WE33 and 91.4 HV1 of WE32 (Fig. 1b).

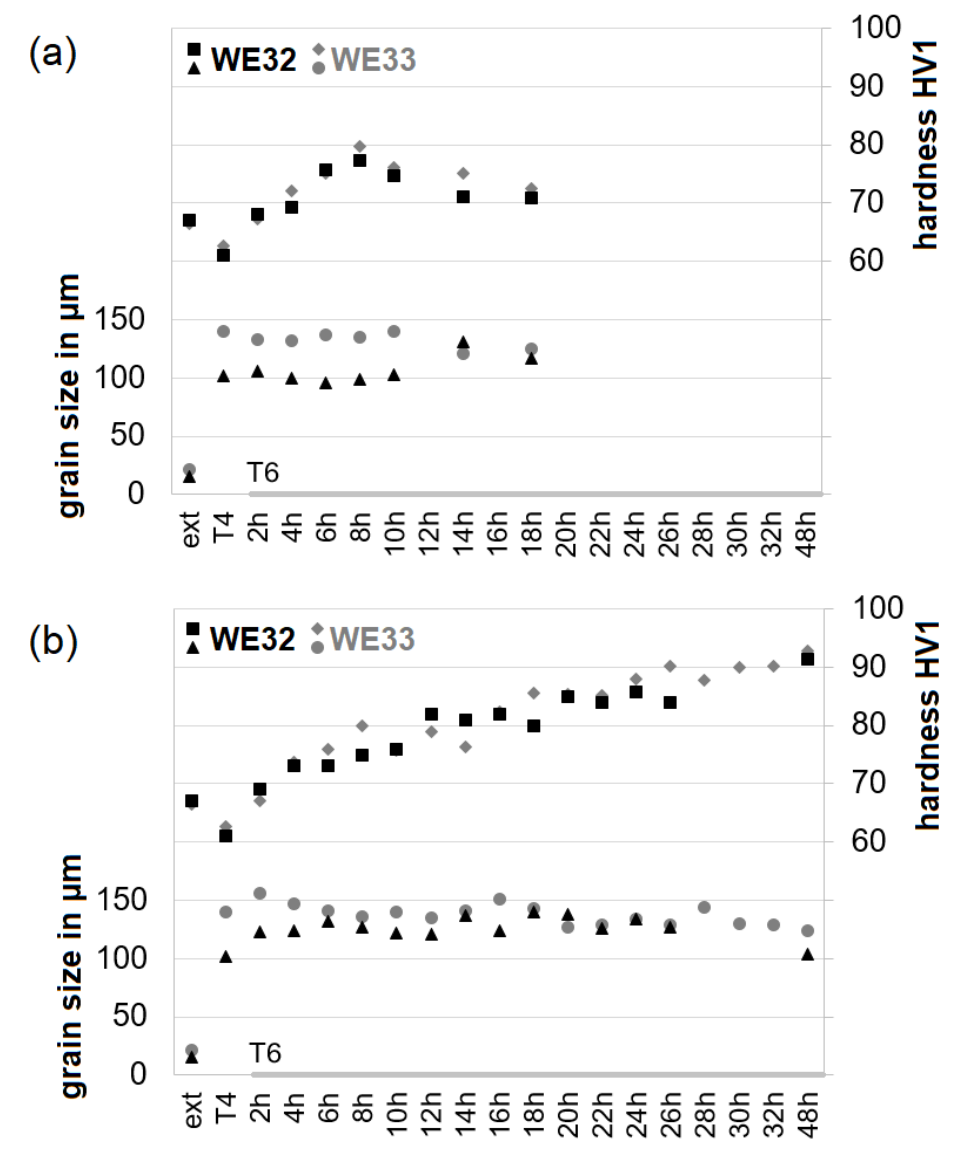

Figure 1. Influence of T4 and T6 heat treatment on hardness and grain size of extruded WE32 and WE33 in dependence of ageing temperature: (a) $250{ }^{\circ} \mathrm{C}$ and (b) $200{ }^{\circ} \mathrm{C}$ 
Fig. 2 shows the microstructural changes during thermomechanical processing and the conditions as-extruded (2a and b), T4 solution heat-treated (Fig. 2c and d), T6 precipitation hardened at $250{ }^{\circ} \mathrm{C}$ for $8 \mathrm{~h}$ (Fig. e and f) and precipitation hardened at $200{ }^{\circ} \mathrm{C}$ for $48 \mathrm{~h}$ (Fig. $2 \mathrm{~g}$ and $\mathrm{h}$ ). The remaining black spots remaining after solution heat treatment indicate that not all intermetallic phases are dissolved. Apart from $\mathrm{Nd}$, where the maximum solubility of $3.6 \mathrm{wt} . \%$ at the eutectic temperature of $545^{\circ} \mathrm{C}[19,20]$ which decreases drastically with decreased temperature, the other alloying elements are below their maximum solubility according their binary phase diagrams. WE33 (Fig. 2d) shows compared to WE32 (Fig. 2c), according to Fig. 1a and $b$, shows a coarser average grain size. Precipitation hardening darkens the optical microscopy images in general (Fig 2e to $\mathrm{h}$ ), indicating the formation of precipitates. There are no significant visible changes of the microstructure during ageing, apart from the visibility of larger precipitates indicated by the black spots after ageing at $250{ }^{\circ} \mathrm{C}$ for $8 \mathrm{~h}$ (see Figure $2 \mathrm{e}$ and $\mathrm{f}$ ). These spots are less significant after ageing at $200{ }^{\circ} \mathrm{C}$ for $48 \mathrm{~h}$, meaning that the precipitates causing the higher hardness of these conditions are much smaller.
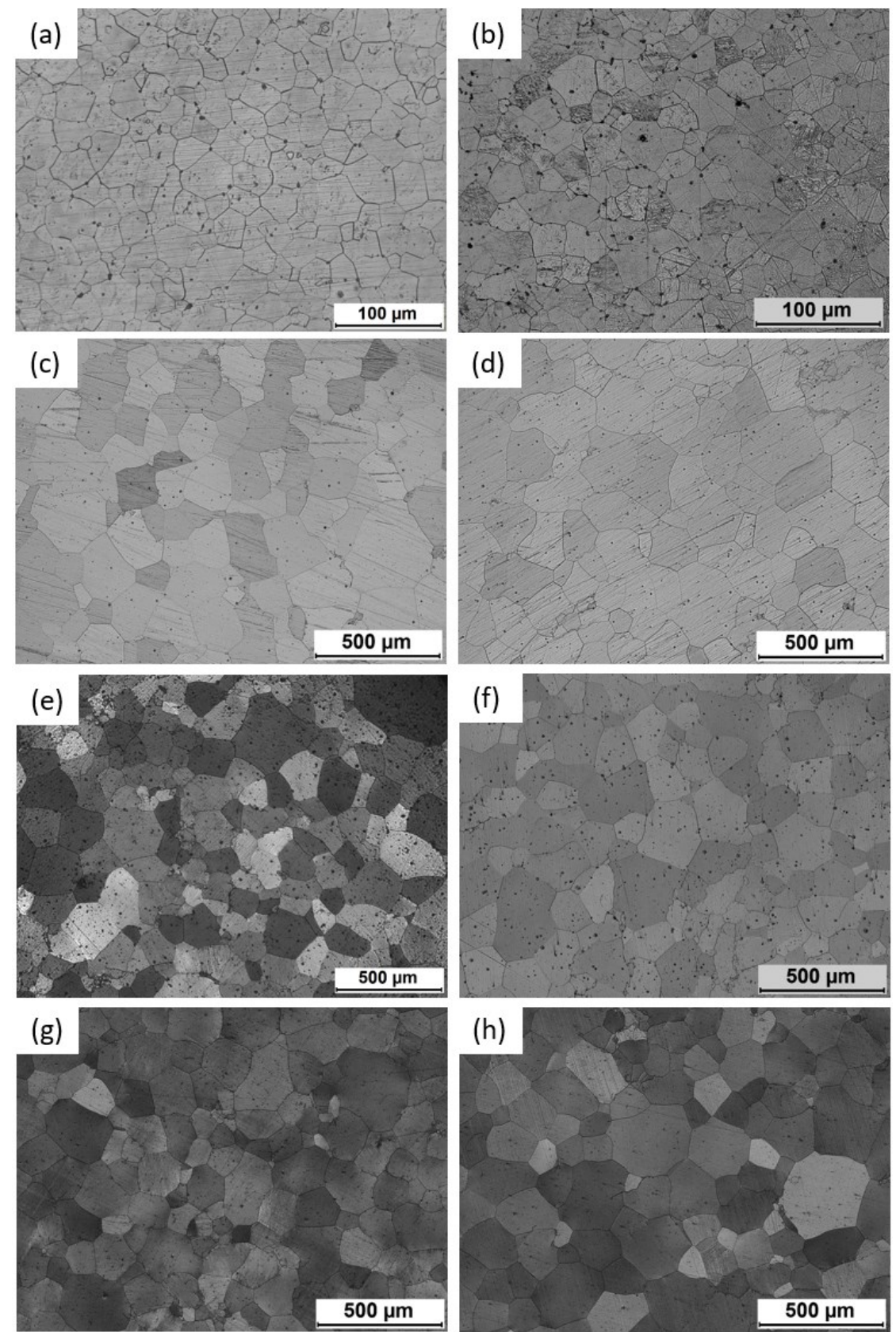

Figure 2. Microstructure of extruded WE32 (a,c,e,g) and WE33 (b,d,f, h): (a,b) extruded, (c,d) T4, (e,f) T6-250 ${ }^{\circ} \mathrm{C}-8 \mathrm{~h}$ and $(\mathrm{g}, \mathrm{h}) \mathrm{T} 6-200^{\circ} \mathrm{C}-48 \mathrm{~h}$ 
In addition to the hardness measurements tensile tests have been conducted. Fig. 3 shows the influence of the heat treatment on strength and ductility. In WE33 in agreement with the higher hardness a slightly higher tensile yield strength (TYS) was observed. The higher ductility (Elongation) of WE33 could be explained by the higher amount of alloying additions, which may increase the activation of the basal slip due to the more random nature of the texture in WE33.

Solution heat treatment (T4) reduces TYS and ultimate tensile strength (UTS) because of dissolution of most intermetallic particles and reduces ductility due to the increased grain size. Unexpectedly the decrease in strength is higher in WE33. In agreement with the hardness, tensile yield strength values exceed the initial strength when precipitation hardening (T6) was done over $8 \mathrm{~h}$ in WE32, ageing at $250{ }^{\circ} \mathrm{C}$ over $8 \mathrm{~h}$ shows a higher strength than at $200{ }^{\circ} \mathrm{C}$ (there are no tensile properties of longer ageing times at $200{ }^{\circ} \mathrm{C}$ ). The elongation reduces after precipitation hardening. Earlier research [21] on WE32 has shown a cup and cone fracture for the extruded condition with typical features of a ductile fracture and a more complex failure mode for the heat-treated conditions: a mix of ductile features like dimples accompanied with cleavage fracture parts in rather larger grains has been found. WE33 shows a slightly higher ageing response, especially at $200{ }^{\circ} \mathrm{C}$ for longer ageing times $(48 \mathrm{~h})$. However, the strength increase is in the expense of the ductility. The smallest value among this series with 12.2 $\%$ has been determined.

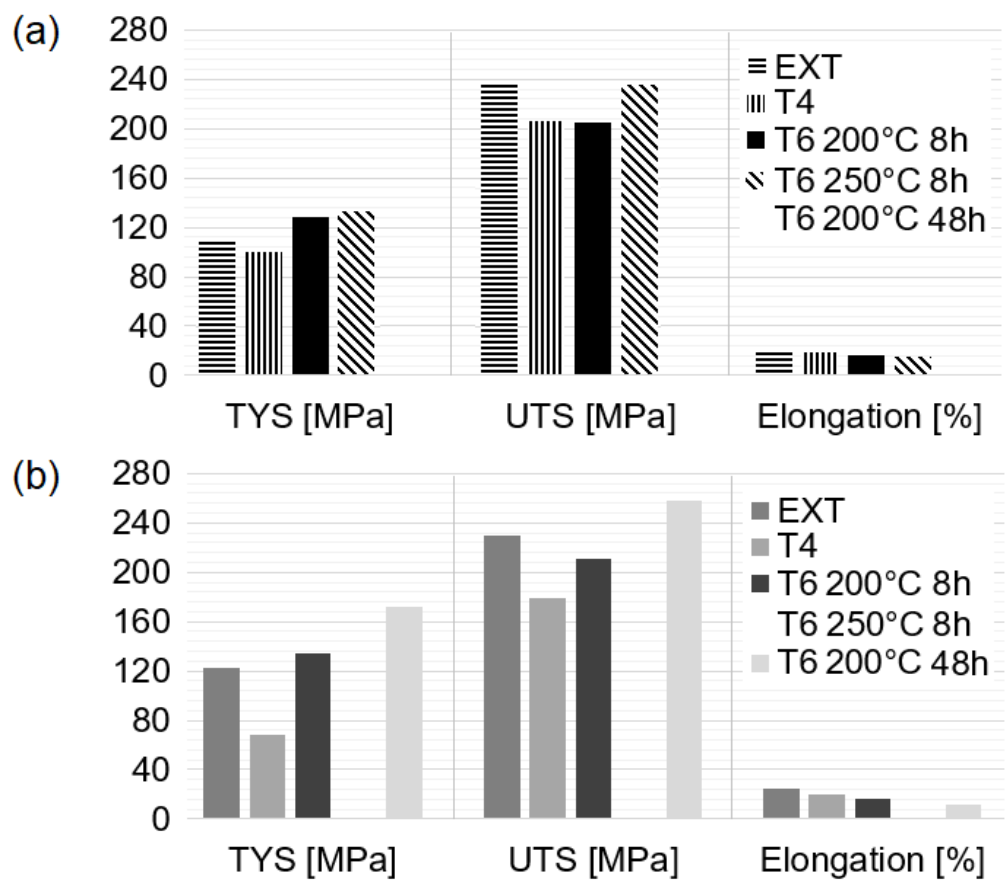

Figure 3. Influence of heat treatment T4 and T6 on tensile properties of extruded WE32 (a) and WE33 (b)

Apart from the T6- $200^{\circ} \mathrm{C}-48 \mathrm{~h}$ condition of WE33, the ultimate tensile strength values do not exceed that of the extruded condition. In [20] a strong increase in maximum grain size has been found in WE32 by using histograms to identify the grain size distribution. The largest grains act as the weakest link in tensile tests; both for strength and ductility.

Beside the mechanical properties, which offer stability of the implant, in biomedical applications the corrosion rate and morphology is also of interest. The corrosion rate needs to fit the healing time of the bone and the corrosion morphology needs to be as uniform as possible. Early failure because of local corrosion is not acceptable. In Fig. 4 the topviews of the corroded samples after immersion are shown. Already by visible appearance it is seen, that the solid solution condition (Fig. $4 \mathrm{~b}$ ) corroded the most among each alloy and WE32 (on the left) corrodes faster than WE33 (on the right). The smallest corrosion attack is seen in the precipitation hardened condition at $200{ }^{\circ} \mathrm{C}$ after $48 \mathrm{~h}$ for both alloys (Fig. $4 \mathrm{~d}$ ). Also the precipitation hardened condition at $250^{\circ} \mathrm{C}$ for $8 \mathrm{~h}$ of WE33 show only a small amount corrosion attack. 
(a)
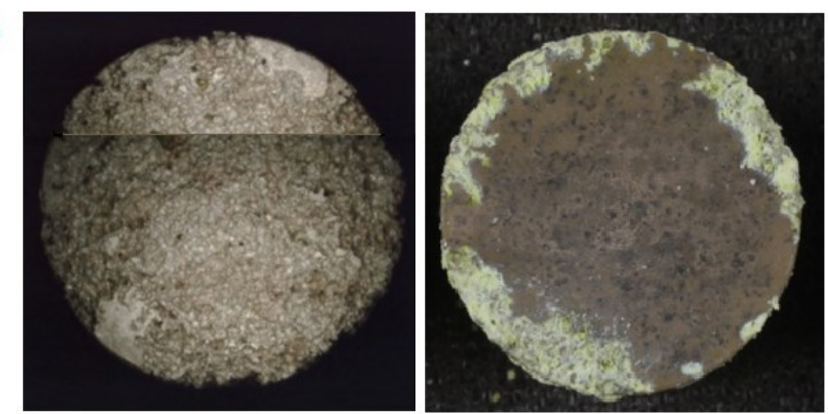

(b)
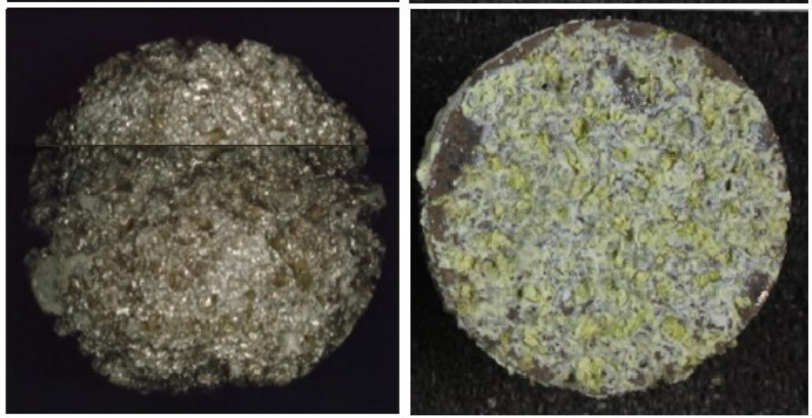

(c)
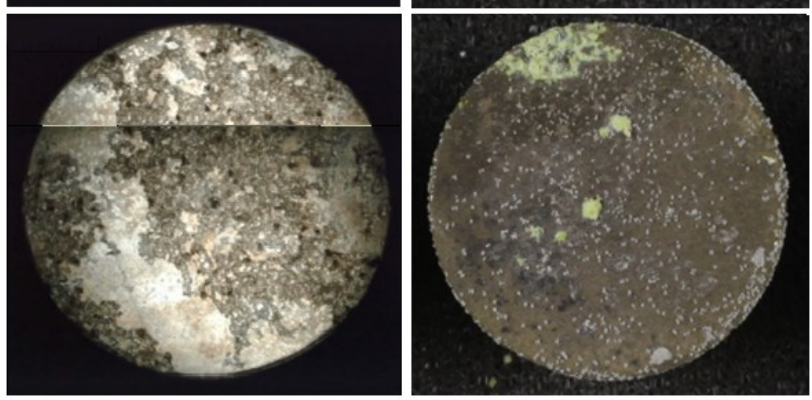

(d)
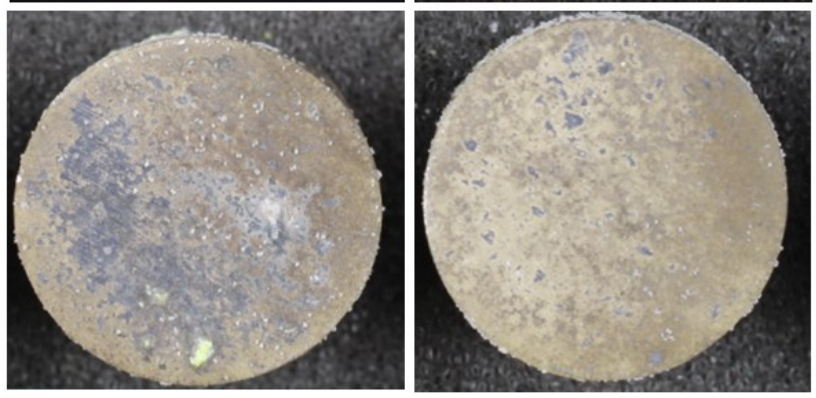

Figure 4. Topviews of corroded samples of WE32 (left) and WE33 (right): (a) extruded, (b) T4, (c) T6-250 ${ }^{\circ} \mathrm{C}-8 \mathrm{~h}$ and (d) T6-200 ${ }^{\circ} \mathrm{C}-48 \mathrm{~h}$

The bar chart in Fig. 5 presents data on the corrosion rate and on the corrosion morphology, evaluated by the pitting factor. WE33 shows an overall smaller corrosion rate: $1.18 \mathrm{~mm} /$ year for extruded, $3.91 \mathrm{~mm} /$ year for T4, $0.18 \mathrm{~mm} / \mathrm{year}$ for T6$250^{\circ} \mathrm{C}-8 \mathrm{~h}$ and $0.44 \mathrm{~mm} /$ year for $\mathrm{T} 6-200^{\circ} \mathrm{C}-48 \mathrm{~h}$, respectively (compared to $14.60 \mathrm{~mm} /$ year for extruded, $25.20 \mathrm{~mm} /$ year for $\mathrm{T} 4,5.30 \mathrm{~mm} /$ year $\mathrm{T} 6-250^{\circ} \mathrm{C}-8 \mathrm{~h}$ for and $0.41 \mathrm{~mm} /$ year for $\mathrm{T} 6-200^{\circ} \mathrm{C}-48 \mathrm{~h}$ of WE32). The increase of alloying elements of $\sim 0.3$ wt. $\% \mathrm{Y}$ and $\sim 0.4$ wt. \% Nd and very small amounts of $\mathrm{Gd}$ and Dy seem to act positive. The increase in the volume fraction of the intermetallic phases, with form grain boundaries networks as well as inner grain secondary phases in the extruded condition improves the formation of a passive layer and provides a shift to a more noble alloy. From EDX-spectra of the secondary phases a stoichiometry of $\mathrm{Mg}_{5}(\mathrm{Gd}, \mathrm{Y}, \mathrm{Dy}, \mathrm{Nd})$ is suggested [21]. The solution heat-treated condition of both alloys show the highest corrosion rate. In TEM work, which is not presented here, no precipitates could be observed. The worst corrosion rate in the solution heat-treated alloy is therefore mainly influenced by growth in grain size. However, here the higher amount of alloying additions acts in a positive manner. 


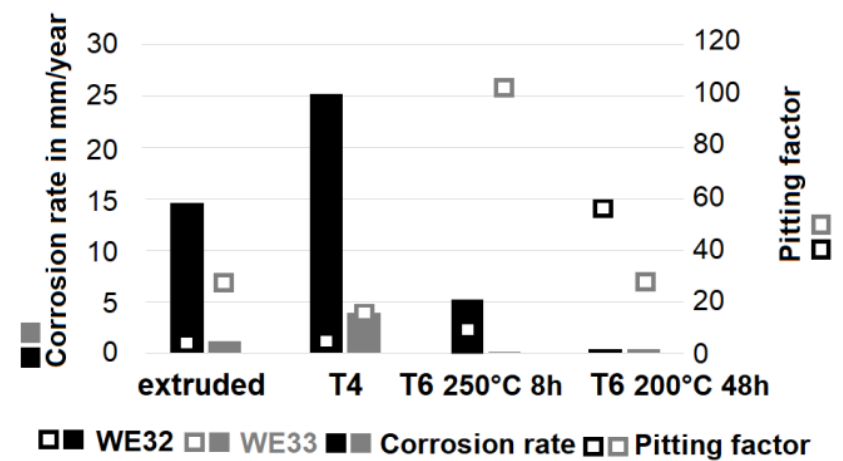

Figure 5. Corrosion rate and pitting factor of WE32 and WE33 after immersion in the conditions: extruded, $\mathrm{T} 4, \mathrm{~T} 6-250^{\circ} \mathrm{C}-8 \mathrm{~h}$ and $\mathrm{T} 6-200^{\circ} \mathrm{C}-48 \mathrm{~h}$

Micro-galvanic corrosion and precipitate strengthening is mostly influenced by the type and morphology of precipitates, its volume fraction and spatial distribution. Especially, the precipitation hardened conditions show reduced corrosion rate - very significant for the ageing treatment at $200{ }^{\circ} \mathrm{C}$ for $48 \mathrm{~h}$. Fine precipitates in a higher volume fraction have been already reported in to give rise to lower corrosion rates [21]. They provide a sufficient amount of micro-galvanic couples between the solid solution phase and precipitates at a shorter distance and are therefore responsible for forming a more pronounced passive layer, which eliminates the corrosion media from the surface. In contrast to these results, a study on Mg- $5 \mathrm{Y}-1.5 \mathrm{Nd}$ by Ma [22] presented that the solid solution condition had the lowest corrosion rate and the aged conditions corroding faster, especially at shorter $(6 \mathrm{~h})$ and longer times $(24 \mathrm{~h})$ compared to the peak aged condition and corrosion pits are found. Firstly of all this study has been done in $3.5 \% \mathrm{NaCl}$, which is stronger than the Ringer solution and the higher amount of $\mathrm{Y}$ causes a much higher amount of the precipitated phases, which act as micro-cathodes not leaving a passive layer to form. The positive influence Gd and Dy is investigated in the study by Ma [22]. However, Ma`s [22] study shows that the peak aged condition $\left(225^{\circ} \mathrm{C}\right.$ for $\left.14 \mathrm{~h}\right)$ with the finest distribution of precipitated phases corrodes the least among the aged conditions.

In addition to the corrosion rate, the pitting factor is presented in Fig. 5 and gives important information on the corrosion morphology. A clear trend can be seen: samples with a high corrosion rate show a low pitting factor and vice versa. Corrosion pits have been found for every heat treatment condition and are mostly of a wide and shallow shape. Only a few pits are undercutting pits. Low pitting factors mean, that local corrosion areas overlap and form a rough surface. A high pitting factor, especially found in the aged condition, indicates that the passive layer is not completely dense and uniform, so that corrosion pits can form and ongoing corrosion consternates on these areas.

To describe the corrosion and its morphology in a different way, the size of the area of corrosion as a percentage as well as the depth of the nine deepest pits can be used. Using the topviews from Fig. 4 it can be summarised that almost the entire surface of the T4 condition of WE32 (97\%) and WE33 (86\%) are corroded. The surface of extruded condition of WE32 is compared to extruded WE33 corroded to significant higher extent: $86 \%$ compared to $23 \%$, respectively. Among the aged conditions only the T6-250 ${ }^{\circ} \mathrm{C}-8 \mathrm{~h}$ samples show a large amount of surface corrosion (Fig. 4c left). As already described, the large precipitates act less positively on the corrosion rate. However, in WE33 the micro-cathodic effect between the precipitates and the $\alpha-\mathrm{Mg}$ matrix seems more favourable for forming a passive layer resulting in less corrosion rate. The size of corroded area agrees very well with the corrosion rate. However, if very deep and large local pitting corrosion occurs (not the case here), such agreement is not necessaryly seen. The 3D images in Fig. 6 are one possibility to evaluate the nine deepest pits, but also the metallographic cross-sections of the corroded samples are used and do evaluate the shape of pits in a better way (undercutting pits are not possible to evaluate by applying confocal light microscopy. However, Fig. 7 shows the nine deepest corrosion pits of the alloy WE33 which according to Fig. 5 shows the smaller overall corrosion rate and lower pitting corrosion resistivity. 
a)

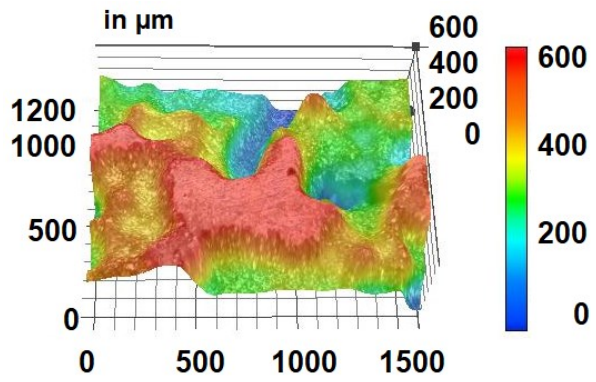

b)

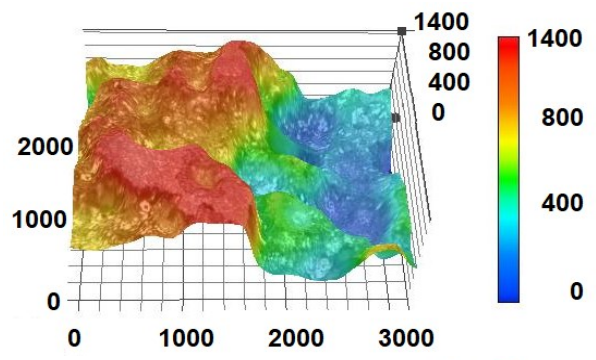

c)

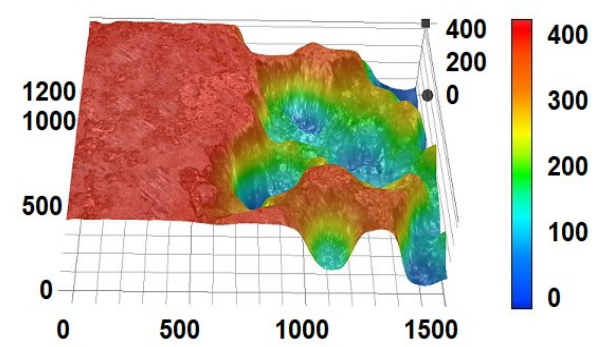

Figure 6. Corrosion morphology of WE32 by 3D imaging: (a) extruded, (b) T4 and (c) T6- $250^{\circ} \mathrm{C}-8 \mathrm{~h}$

Fig. 7 shows the following: The solid solution condition (T4) of WE33 clearly shows the deepest corrosion pits, which remains higher up to pit number 9. Also, the extruded condition of WE33 has at least nine pits deeper than $200 \mu \mathrm{m}$. The heattreated conditions T6- $250^{\circ} \mathrm{C}-8 \mathrm{~h}$ of WE33 start off rather high, but only a few pits are deep. Ageing WE33 at $200{ }^{\circ} \mathrm{C}$ over 48 $\mathrm{h}$ shows the lowest depth of corrosion pits. Whereas, the pits in the aged condition of WE32 at $200{ }^{\circ} \mathrm{C}$ over $48 \mathrm{~h}$ start off rather deep; but only a few are deeper than $200 \mu \mathrm{m}$. That means that the pitting corrosion resistivity is rather low, and a strong local corrosion occurs after the first pits have formed.

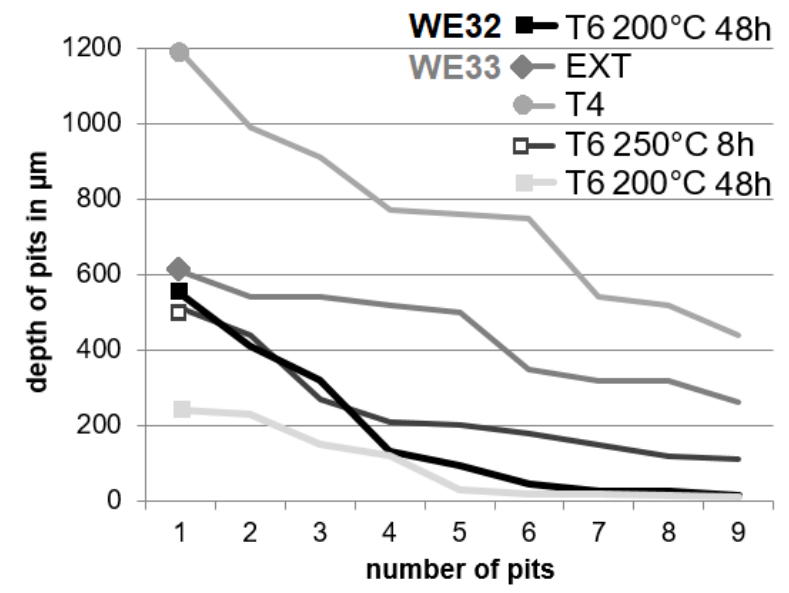

Figure 7. 9 deepest corrosion pits after immersion in WE32 in T6-200 ${ }^{\circ} \mathrm{C}-48 \mathrm{~h}$ and WE33 in the conditions: extruded, T4, T6-250 ${ }^{\circ} \mathrm{C}-8 \mathrm{~h}$ and T6$200^{\circ} \mathrm{C}-48 \mathrm{~h}$

Combining all the data for corrosion rate, deepest pits and pitting factor in relation, the following can be stated for WE33: the extruded condition shows medium ranged pits $(\sim 600 \mu \mathrm{m})$, has a low corrosion rate $(\sim 1.2 \mathrm{~mm} /$ year $)$ and therefore a medium pitting factor of 26 has been found. The solid solution treated condition (T4) shows the deepest pits (up to $1200 \mu \mathrm{m}$ ), but 
since the corrosion rate is higher, a lower pitting factor of 15 is found. This is a good example that deep pits do not consequently mean high pitting factors: the ongoing corrosion forms overlapping corrosion pits, resulting in medium ranged pits and causing a fast but uniform corrosion. Ageing WE33 at $250^{\circ} \mathrm{C}$ for $8 \mathrm{~h}$ results in one of the lowest corrosion rates, but medium sized pits; therefore the pitting factor is the highest among all samples investigated. Ageing WE33 at $200{ }^{\circ} \mathrm{C}$ for $48 \mathrm{~h}$ led to the smallest pits found, the corrosion rate is also very low, and so a moderate pitting factor can be found. According to Fig. 7, WE32 at the same ageing condition shows pits in the medium range at a similar low corrosion rate, the pitting factor is found to be higher. So it appears, that the higher volume fraction of fine precipitates in WE33 compared to WE32 is more beneficial to the corrosion rate in immersion in general, but also on the resistance to pitting corrosion.

Fig. 8 shows the influence of heat treatment on corrosion behaviour of WE32 by representative current density-potential curves. They have been evaluated with potentiodynamic polarization. To cause a high anodic dissolution, they were run from a potential of $-2000 \mathrm{mV}$ to $500 \mathrm{mV}$. The fine grained extruded material has a current density at around $26 \mathrm{~mA} / \mathrm{cm}^{2}$ at 500 $\mathrm{mV}$. The solid solution treated condition (T4) shows the highest current density values of $30 \mathrm{~mA} / \mathrm{cm}^{2}$ at $500 \mathrm{mV}$. Both curves show no visible breakdown potential. In WE32 the solid solution treated condition (T4) shows a higher current density from the start, here the coarser grain size causes higher corrosion. Due to similar grain sizes, the aged conditions corrode with a similar current density-potential curves, but at lower current density values due to the presence of precipitates. At a current density of $-500 \mathrm{mV}$ a pseudo passivation can be seen. The current density still increased with increasing potential, but at a much lower rate. The $\mathrm{T} 6-200^{\circ} \mathrm{C}-48 \mathrm{~h}$ condition shows a decrease in current density with increasing potential from $250 \mathrm{mV}$ onwards. Pseudo-passivation is usually a result of a non-uniform passive layer and a hint of pitting corrosion. The potential was kept below $500 \mathrm{mV}$ - higher potentials would be unrealistic for implants within the body environment. A statement on the potential of breakdown can therefore not be given.

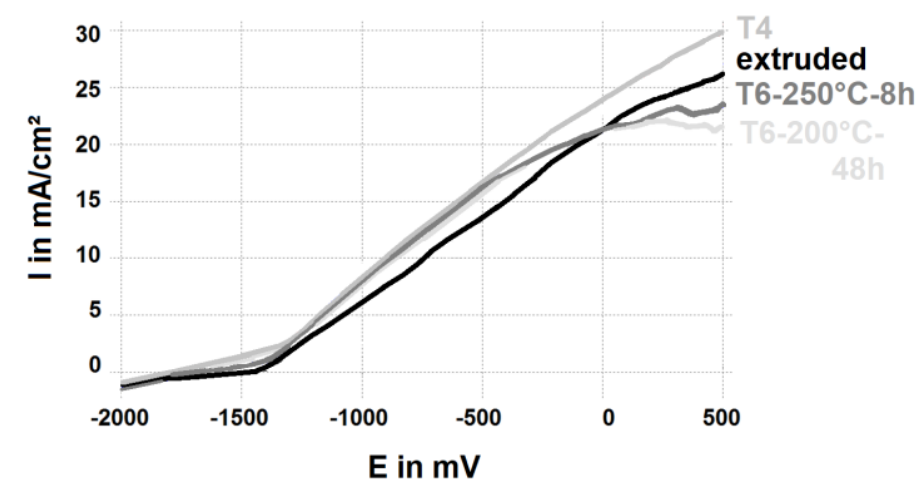

Figure 8. Influence of heat treatment on corrosion measured with potentiodynamic polarization on the example of WE32 in the conditions: extruded, solution heat-treated T4 and precipitation hardened $\mathrm{T} 6$ at $250^{\circ} \mathrm{C}$ for $8 \mathrm{~h}$ and $\mathrm{T} 6$ at $200{ }^{\circ} \mathrm{C}$ for $48 \mathrm{~h}$

The corroded area was evaluated by using the cross-sectional macrograph of the corroded end face of the cylindrical samples. The samples were ground through the cross-section of the cylinder without removing the corrosion product. Since only the inner region of the cylinder face was corroded the initial surface (an outer ring of $1.5 \mathrm{~mm}$ ) could be used as a reference. Sorting WE32 by the corroded amount of corroded area (evaluated from the cross-sectional micrograph) following different treatments can be arranged in the following order: T4 $\left(1.51 \mathrm{~mm}^{2}\right)>$ extruded $\left(1.35 \mathrm{~mm}^{2}\right)>\mathrm{T} 6-250^{\circ} \mathrm{C}-8 \mathrm{~h}\left(1.24 \mathrm{~mm}^{2}\right)>\mathrm{T} 6-$ $200^{\circ} \mathrm{C}-48 \mathrm{~h}\left(0.97 \mathrm{~mm}^{2}\right)$. This order agrees with the corrosion rate of the immersion tests and with the value of the current density at $500 \mathrm{mV}$ in Figure 12. However, not only the end value of the curves determines the corrosion rate, but also the curve itself. Sorting WE33 by the corroded area gives a different picture: extruded $\left(1.60 \mathrm{~mm}^{2}\right)>\mathrm{T} 6-200^{\circ} \mathrm{C}-48 \mathrm{~h}\left(0.74 \mathrm{~mm}^{2}\right)>$ $\mathrm{T} 6-250^{\circ} \mathrm{C}-8 \mathrm{~h}\left(0.70 \mathrm{~mm}^{2}\right)>\mathrm{T} 4\left(0.67 \mathrm{~mm}^{2}\right)$; where the values of the heat-treated conditions are very close to each other. The extruded condition of WE33, contrary to the immersion test results and in contrast to WE32, shows a significantly higher corrosion rate. An explanation for that cannot be given at the present. Data from the polarisation and immersion measurements are found to be different in previous research [23]. Polarisation causes anodic corrosion by the increase in the applied voltage, in immersion the material is left at its equilibrium environment. It is possible that during polarisation the forming passivation layer is attacked by the increased voltage providing a potential difference, finally causing the passivation layer to breakdown. The values of the corrosion rate evaluated by immersion do not show an overall agreement to the values of corroded area from polarisation (since the measurement methods are different, the absolute values cannot be compared anyway). However, the values show that the corrosion rate of the $\mathrm{T} 6-200^{\circ} \mathrm{C}-48 \mathrm{~h}$ is very low in immersion and polarisation (fine precipitates act beneficial on passivation). 
Fig. 9 (a to d) shows the representative morphologies of the corroded areas of the cross-sections for both alloys: WE32 on the left row and WE33 on the right row. The corroded surface appears rather non-uniform, showing roughness is indicative of corrosion pits. Pitting corrosion can be seen in each micrograph, mostly where the depth is not much larger than the width of the opening pit. A small amount of under cutting can be observed. However, these pits do not appear to be in a critical narrow and very deep shape.

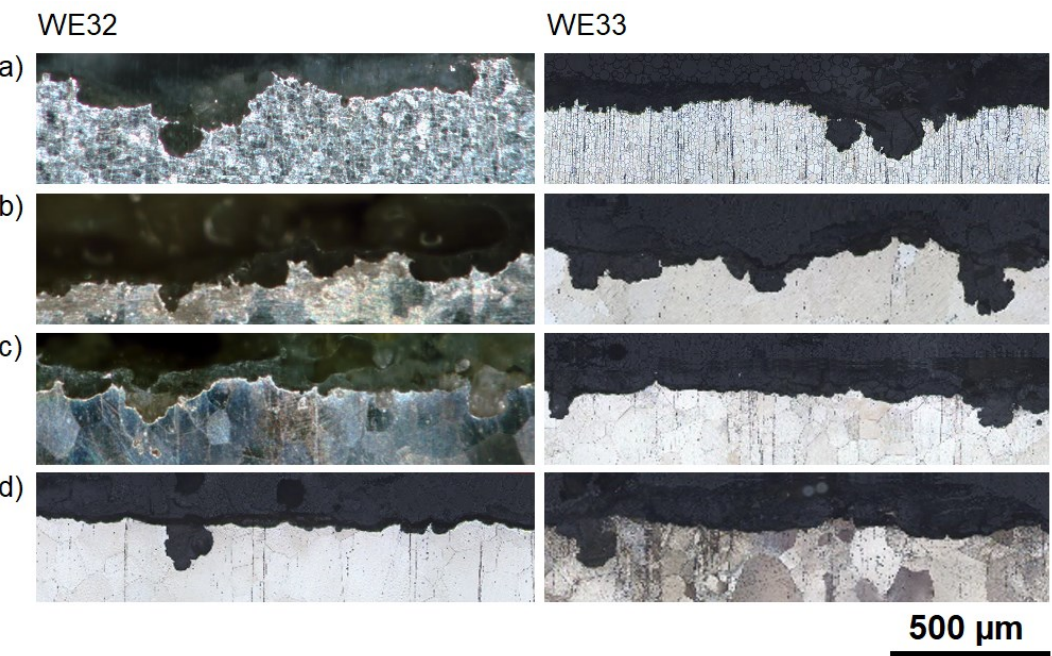

Figure 9. Cross-sectional micrographs showing corrosion morphology after polarisation of WE32 and WE33: (a) extruded, (b) T4, (c) T6$250^{\circ} \mathrm{C}-8 \mathrm{~h}$ and $(\mathrm{d}) \mathrm{T} 6-200^{\circ} \mathrm{C}-48 \mathrm{~h}$

Figure 10 shows the pitting factors of the alloys WE32 and WE33 and their dependence on the heat treatment condition. Both extruded conditions show pitting factor around 3. Ageing at $\mathrm{T} 6-200^{\circ} \mathrm{C}-48 \mathrm{~h}$ causes the highest pitting factors: with a lower corrosion rate as a result of passivation (see Fig. 8) the pitting factor increases when the oxide layer is obviously not dense enough, which agrees with the immersion tests. This shows that the alloy design should be done in a way, that the passive layer is dense and uniform. To achieve this retention, a small grain size will be beneficial.

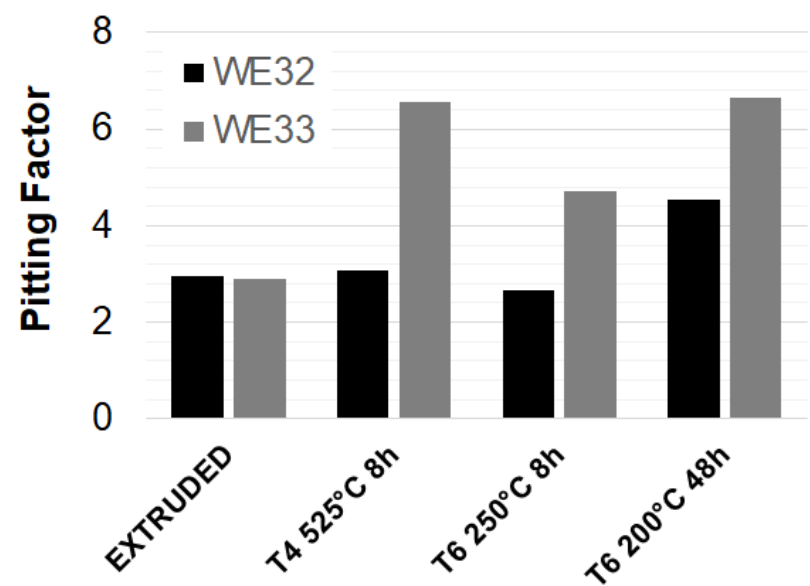

Figure 10. Pitting factor of WE32 and WE33 after polarisation in the conditions: extruded, $\mathrm{T} 4, \mathrm{~T} 6-250^{\circ} \mathrm{C}-8 \mathrm{~h}$ and $\mathrm{T} 6-200^{\circ} \mathrm{C}-48 \mathrm{~h}$

\section{Summary}

This study provides a very detailed investigation of Mg-RE alloys concerning mechanical and corrosion properties. It shows that the precipitation hardening in two Mg-Y-Nd-Gd-Dy (WE32 and WE33) alloys is an effective mechanism to strengthen the material as well as to modify the corrosion morphology by changing the amount and size of second phases. The mechanical properties like tensile data and hardness show that the higher the alloy element result in a higher the strength (values up to $170 \mathrm{MPa}$ for TYS) with decreasing ductility (down to $12 \%$ ). Biodegradable implants should show a sustainable (for the removal of $\mathrm{H}_{2}$ from the implant site) corrosion rate, and especially when exposed to mechanical loading, the implant material should be free of pitting corrosion. 
A short ageing time of $8 \mathrm{~h}$ is observed for peak hardness at a temperature of $250{ }^{\circ} \mathrm{C}$. Aging at $200{ }^{\circ} \mathrm{C}$ leads to a longer ageing time to peak hardness, at $48 \mathrm{~h}$ the highest hardness has been found. The peak hardening causes hardness values exceeding the initial extruded condition, especially for the lower ageing temperature. Peak hardening reduces ductility mostly due to the large grain growth during solution heat treatment from an average of $15 \mu \mathrm{m} / 25 \mu \mathrm{m}$ to $100 \mu \mathrm{m} / 150 \mu \mathrm{m}$. Grain growth during ageing is not significant.

The corrosion behavior in Ringer Acetate solution was evaluated, using immersion tests and potentiodynamic polarization as well as by evaluating corrosion morphology and the corroded area using cross-section micrographs. The highest corrosion rate in immersion was found in the T4 condition, to a much higher extent in WE32. Precipitation hardening shows reduced corrosion rate, especially for the ageing treatment of $200^{\circ} \mathrm{C}$ for $48 \mathrm{~h}$. A higher volume fraction of fine precipitates provides a useful distance of micro-galvanic couples between the solid solution phase. These precipitates are therefore responsible for forming a more pronounced passive layer, which eliminates the corrosion media from the surface. One another hand the passive layer must be completely densified and uniform to avoid pitting corrosion. The aged condition in this study shows rather high pitting factors. However, very deep and narrow pits, which would become large stress intensifiers under mechanical loading, have not been found.

To conclude the study presented here: a fine dispersion of precipitates through optimized precipitation hardening is suggested for improved mechanical properties and corrosion rate. The higher amount of alloying additions in WE33 acts in a positive manner on the properties. However, special attention must be also paid to the homogeneous corrosion morphology. The alloys in this study does not show the best resistance to pitting corrosion. Further modification of the alloy and process design should aim to keep the grain size as small as possible.

\section{Acknowledgement}

The authors thank the Extrusion Center Berlin in Germany for extruding the bars and acknowledge the support of Hartmut Habeck and Benjamin Clausius from UAS Stralsund. Julia Bode from TU Bergakademie Freiberg, Germany, is thanked for ICP-OES measurements.

\section{References}

1. D. Zhao et al. "Current status on clinical applications of magnesium-based orthopaedic implants: A review from clinical translational perspective" Biomaterials 112 (2016) 287-302.

2. A.D. Sudholz et al. "Electrochemical behaviour and corrosion of Mg-Y alloys" Corrosion Science 53/6 (2011) 2277-2282.

3. M. Staiger et al. "Magnesium and its alloys as orthopedic biomaterials: A review" Biomaterials 27 (2006) 1728-1734.

4. N. Hort et al. "Magnesium alloys as implant materials - Principles of property design for Mg-RE alloys," Acta Biomaterialia 6 (2010) 1714-1725.

5. H. Kalb et al. "Impact of microgalvanic corrosion on the degradation morphology of WE43 and pure magnesium under exposure to simulated body fluid" Corrosion Science 57 (2012) 122-130.

6. J.M Seitz et al. „Magnesium-based compression screws: a novelty in the clinical use of implants” JOM The journal of the Minerals, Metals \& Materials Society 68/4 (2016) 1177-1182.

7. C. Rapetto and M. Leoncini „Magmaris: a new generation metallic sirolimus-eluting fully bioresorbable scaffold: present status and future perspectives" Journal of Thoracic Disease 9/9 (2017) 903-913.

8. Magnesium Elektron UK, data sheet 467

9. D. Tolnai et al. "In situ synchrotron diffraction of the solidification of Mg4Y3Nd" Materials Letters 102-103 (2013) 62-64.

10. B. Smola et al. "Structural aspects of high performance Mg alloys design" Materials Science and Engineering A324 (2002) 113-117.

11. L.L. Rokhlin "A study of properties of high-strength magnesium alloy of the Mg-Y-Nd-Zr system" Metal Science and Heat Treatment 52 (2011) 588-591. 
12. Y.H. Kang et al. "Microstructures and mechanical properties of the age hardened Mg-4.2Y-2.5Nd-1Gd-0.6Zr (WE43) mircoalloyed with Zn" Journal of Magnesium and Alloys 2 (2014) 109-114.

13. Metals Handbook Ninth Edition, Failure Analysis and Prevention, American Society for Metals, Standard Guide for Examination and Evaluation of Pitting Corrosion, ASTM G46-94 (Reapproved 2005); Materials Performance (2008) 176179.

14. R.W. Revie and H.H Uhlig "Corrosion and corrosion control" John Wiley \& Sons, (2008) page 17.

15. E. Mecozzi "Corrosion potentials in CO2 infrastructure" IMPACTS project, SINTEF Energy Research (2015).

16. V. Kree et al. "The Metallographical Examination of Magnesium Alloys" Practical Metallography 41 (2004) 233-246.

17. N. Li et al. "Comparative study on corrosion behaviour of pure Mg and WE43 alloy in static, stirring and flowing Hank's solution" Corrosion Engineering, Science and Technology 47 (2012) 346-351.

18. P. Maier et al. "Microstructural changes of an extruded WE33 alloy during precipitation hardening" Proceedings of Conference on Magnesium alloys and its application (2018)

19. Y. Zheng "Magnesium Alloys as Degradable Biomaterials" CRC Press Taylor \& Francis Group (2015) 345.

20. S. Gorsse et al. "A Thermodynamic Assessment of the Mg-Nd System Using Random and Associate Models for the Liquid Phase" Journal of Alloys and Compounds 392 (2005) 253-262.

21. P. Maier et al. "Influence of precipitation hardening in Mg-Y-Nd on mechanical and corrosion properties" JOM The journal of the Minerals, Metals \& Materials Society 68/4 (2016) 1183-1190.

22. X. Ma et al. "Effect of Heat Treatment on Corrosion Behaviors of Mg-5Y-1.5Nd Alloys" International Journal of Electrochemistry, ID 7097589 (2016) 9 pages.

23. P. Maier et al. "Solid solution treatment on mechanical and corrosion of extruded Mg5Gd compared to pure Mg" Contributed papers from Materials Science and Technology - MS\&T17 (2017) 76-83. 